\title{
BH3 Mimetics for the Treatment of Prostate Cancer
}

\author{
Philipp Wolf* \\ Department of Urology, Medical Center - University of Freiburg, Faculty of Medicine, University of Freiburg, Freiburg, \\ Germany
}

Despite improved diagnostic and therapeutic intervention, advanced prostate cancer (PC) remains incurable. The acquired resistance of PC cells to current treatment protocols has been traced to apoptosis resistance based on the upregulation of anti-apoptotic proteins of the Bcl-2 family. The use of BH3 mimetics, mimicking proapoptotic activator or sensitizer proteins of the intrinsic apoptotic pathway, is therefore a promising treatment strategy. The present review gives an overview of preclinical and clinical studies with pan- and specific BH3 mimetics as sensitizers for cell death and gives an outlook how they could be effectively used for the therapy of advanced PC in future.

\section{Keywords: prostate cancer, apoptosis, $\mathrm{Bcl}-2$ proteins, $\mathrm{BH} 3$ mimetics, therapeutic resistance}

\section{OPEN ACCESS}

Edited by:

Owen McCarty,

Oregon Health and Science

University, United States

Reviewed by:

Lilian Varricchio,

Icahn School of Medicine at Mount

Sinai, United States

Frank Arfuso,

Curtin University, Australia

${ }^{*}$ Correspondence:

Philipp Wolf

philipp.wolf@uniklinik-freiburg.de

Specialty section:

This article was submitted to

Cancer Molecular Targets and Therapeutics,

a section of the journal

Frontiers in Pharmacology

Received: 26 June 2017 Accepted: 07 August 2017

Published: 18 August 2017

Citation:

Wolf P (2017) BH3 Mimetics for the Treatment of Prostate Cancer.

Front. Pharmacol. 8:557.

doi: 10.3389/fphar.2017.00557

\section{INTRODUCTION}

Prostate cancer remains the second most common cancer in men worldwide. About 1.1 million new cases are detected every year, accounting for $15 \%$ of all diagnosed cancers. As the fifth leading cause of cancer deaths, PC was responsible for an estimated 307,000 deaths representing 6.6\% of the total cancer mortality (Ferlay et al., 2015). Locally restricted tumors can be successfully treated by radical prostatectomy, brachytherapy, external beam radiation, or active surveillance. In advanced PC, ADT is administered as first-line therapy. However, its median duration response of up to 18 months is limited, because virtually all patients develop CRPC with biochemical progress and high therapeutic resistance (Halabi et al., 2014; Katzenwadel and Wolf, 2015). In 2004, only a moderate overall survival benefit of about 3 months was reached in two independent phase 3 trials with docetaxel chemotherapy in metastatic CRPC (Petrylak et al., 2004; Tannock et al., 2004). Despite improved diagnostic and therapeutic procedures and improvements in terms of treatment sequencing and combinations, CRPC remains incurable. Studies evidence that a main factor for the acquired resistances to ADT, radiation, and chemotherapy is the resistance of PC cells to apoptosis (Gjertsen et al., 1998; Stein, 1999; DiPaola et al., 2001). Therefore, restoration of apoptosis represents a promising strategy for the future treatment of advanced PC.

\section{REGULATION OF APOPTOSIS BY BCL-2 FAMILY MEMBERS}

Apoptosis, the programmed cell death, is a highly regulated and controlled process of multicellular organisms for the elimination of surplus or damaged cells to preserve tissue and organ homeostasis (Kiraz et al., 2016). Key regulators of the intrinsic apoptotic pathway are proteins of the B-cell

Abbreviations: 2DG, 2-deoxyglucose; ADT, androgen deprivation therapy; CRPC, castration resistant prostate cancer; JNK, c-Jun N-terminal kinase; MSeA, methylseleninic acid; PAB, pseudolaric acid; PC, prostate cancer. 
lymphoma 2 (Bcl-2) family (Youle and Strasser, 2008). According to their function in the apoptosis network, Bcl-2 family members can be divided into two different subgroups: the anti-apoptotic proteins (Bcl-2, Bcl-w, Bcl-xl, and $\mathrm{Mcl}-1$ ) and the pro-apoptotic proteins. The latter group comprises the effectors (Bax and Bak), the activators (BID, BIM, and PUMA), and the sensitizers (BAD and NOXA) (Figure 1A). Structural analyses showed that the anti-apoptotic proteins share four regions of sequence homology dubbed Bcl-2 homology domains (BH1-4). The domains BH1-3 form a hydrophobic binding pocket into which the effectors can bind via their $\mathrm{BH} 3$ domain. The activator and sensitizer proteins hold only the $\mathrm{BH} 3$ domain and are therefore called $\mathrm{BH} 3$-only proteins (Czabotar et al., 2014).

In non-apoptotic cells, the effectors are inhibited by binding of the anti-apoptotic proteins. Upon induction of apoptosis, the $\mathrm{BH} 3$ only proteins are transcriptionally or post-translationally activated and bind via their $\mathrm{BH} 3$ domain to the binding pocket of the anti-apoptotic proteins to free the effectors. Taking different models into consideration, the activators are believed to directly activate Bax and Bak and to inhibit the anti-apoptotic proteins. The sensitizers, which cannot directly interact with the effectors, can also neutralize the anti-apoptotic proteins. Displacing Bax and Bak from the anti-apoptotic proteins leads to their homo-oligomerization and a formation of pores in the outer mitochondrial membrane. This event is termed mitochondrial outer membrane permeabilization (MOMP) and marks the point of no return in apoptosis. MOMP is followed by cytochrome $c$ release from the mitochondria and activation of initiator caspase-9 and downstream effector caspases (Youle and Strasser, 2008).

\section{APOPTOSIS RESISTANCE IN PROSTATE CANCER}

Resistance against apoptosis is a significant hallmark of cancer and contributes to tumor formation, survival, and therapeutic resistance (Cory et al., 2003; Hanahan and Weinberg, 2011). The acquired resistance of advanced PC to current treatment protocols (ADT, radiation, and chemotherapy) has been associated with apoptosis resistance of PC cells, especially based on an upregulation of the anti-apoptotic Bcl-2 family members (Gjertsen et al., 1998; Stein, 1999; Lebedeva et al., 2000; DiPaola et al., 2001). This has been proven by the fact that the treatment of hormone-naïve PC with ADT plus docetaxel, which primarily affects Bcl-2 expression by phosphorylation (Pienta, 2001; Boudny and Nakano, 2002), led to a survival benefit of about 13-15 months compared to the ADT monotherapy (Sweeney et al., 2015; Wolf, 2017).

In an immunohistological study, $\mathrm{Bcl}-2$ was detected in $25 \%$ of human prostate adenocarcinomas and shown to be more present in high grade tumors (Gleason grade $8-10 ; 41 \%)$ and nodal metastases (38\%) compared to lower grade primary tumors (Gleason 2-7; 16\%; $P<0.05$ ) (Krajewska et al., 1996). Bcl-2 expression was also associated with lower biochemical-free survival in patients with advanced PC undergoing ADT (Anvari et al., 2012).

Bcl-xl was detected in all tumors tested and more intense immunostaining was observed in the high grade primary tumors and in metastases compared to prostatic intraepithelial neoplasia $(\mathrm{PIN})$ and low grade neoplasms $(P<0.0001)$. Moreover, it was more abundant in samples of patients with CRPC (Krajewska et al., 1996; Castilla et al., 2006).

Mcl-1 was expressed in $81 \%$ of the tumors, compared with only $38 \%$ cases of PIN $(P<0.001)$. A higher percentage of Mcl-1 positive cells was observed in high grade tumors and metastases than in lower grade tumors $(P=0.025)$ (Krajewska et al., 1996). Studies with different PC cell lines verified that, compared to Bcl-2, Bcl-xl and Mcl-1 protected the cells from different chemotherapeutic agents (Lebedeva et al., 2000; Reiner et al., 2015).

Interestingly, the pro-apoptotic effectors Bax and Bak were shown to be present in $95-100 \%$ and $77.5 \%$, respectively, of all PCs tissues evaluated regardless of tumor grade (Krajewska et al., 1996; Yoshino et al., 2006; Anvari et al., 2012). Moreover, mutations of the Bak and Bax genes are rare events in PC (Yoshino et al., 2006).

\section{BH3 MIMETICS FOR THE TREATMENT OF PROSTATE CANCER}

\section{Pan-BH3 Mimetics}

Due to their overexpression and their significant role in the induction of apoptosis, anti-apoptotic Bcl-2 proteins can act as suitable targets in cancer cells for the restoration of apoptosis. Bcl-2 family inhibition encompasses two main strategies: (i) knockdown and (ii) the use of synthetic low-molecular agents mimicking the $\mathrm{BH} 3$ only proteins. The latter are called $\mathrm{BH} 3$ mimetics or Bcl-2 inhibitors and can directly bind and thus inhibit the anti-apoptotic proteins (Scarfo and Ghia, 2013) (Figure 1B).

In preclinical and clinical studies against $\mathrm{PC}$ the natural BH3 mimetics (-)-Gossypol [R-(-)-enantiomer of gossypol, AT101], BI-97C1 (Sabutoclax), and GX15-070 (Obatoclax) were used. They act as pan-Bcl-2 inhibitors targeting the four major anti-apoptotic Bcl-2 proteins Bcl-2, Bcl-xl, $\mathrm{Mcl}-1$, and Bcl-w (Wolter et al., 2006; Lessene et al., 2008; Wei et al., 2010; Joudeh and Claxton, 2012) (Table 1). (-)-Gossypol alone inhibited cell growth and induced the intrinsic apoptosis of PC cells with $50 \%$ inhibitory concentration values $\left(\mathrm{IC}_{50}\right)$ in the low $\mu \mathrm{M}$ range (Volate et al., 2010). Mechanistically, a blocking of the interactions of $\mathrm{Bcl}-\mathrm{xl}$ with $\mathrm{Bax}$ or BAD and enhanced PUMA and NOXA levels were detected. Moreover, it synergistically increased the antitumor activity of docetaxel (Meng et al., 2008; Volate et al., 2010). The multikinase inhibitor Sorafenib synergistically suppressed the growth of PC cells in combination with (-)-gossypol by Mcl-1 inhibition and Bak activation (Lian et al., 2012). The use of valproic acid, a histone deacetylate 
$\mathbf{A}$

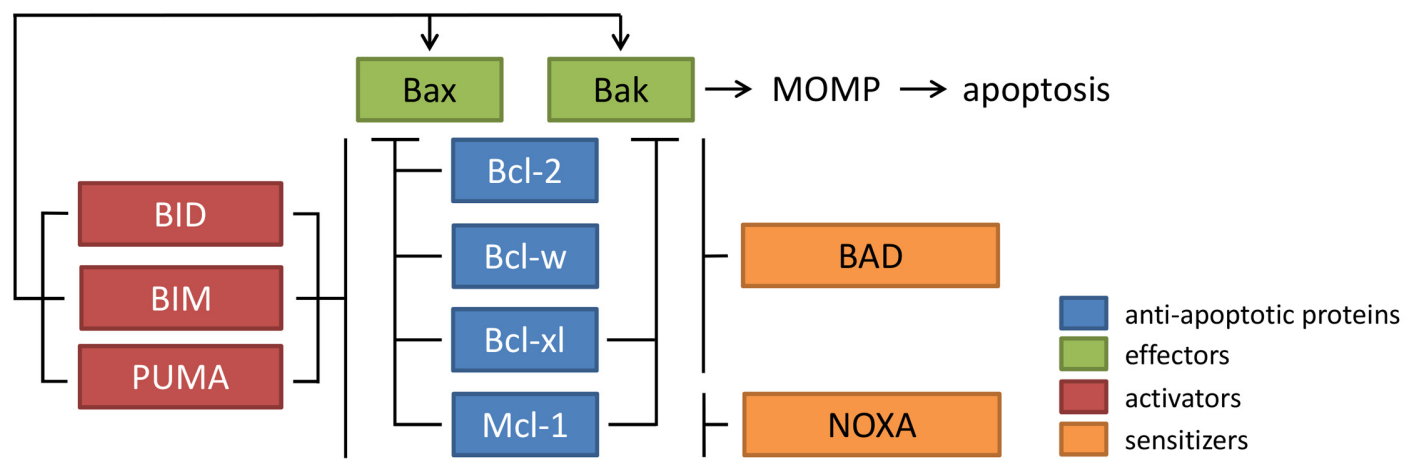

B

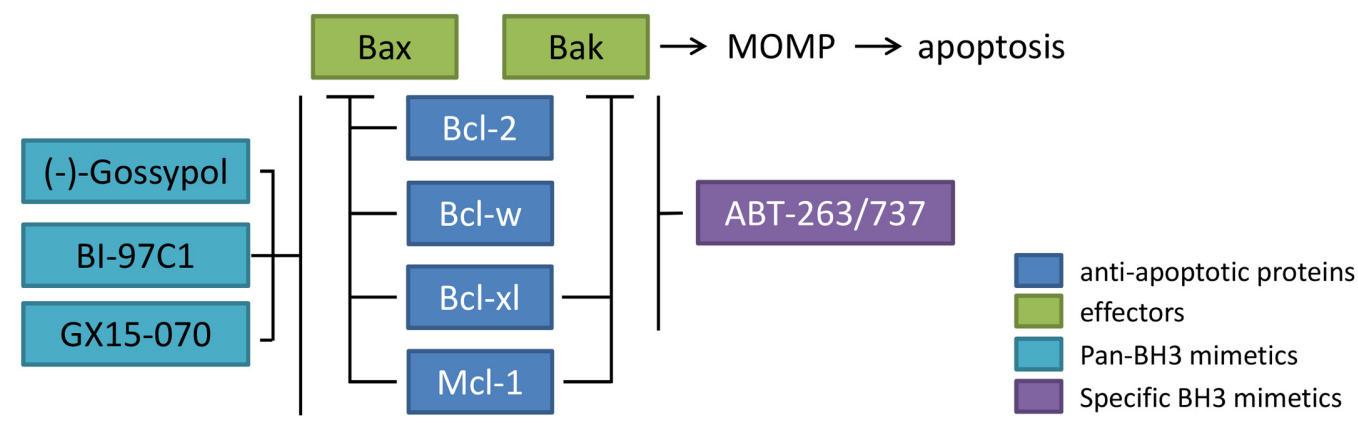

FIGURE 1 | Schematic representation of the interactions between different members of the Bcl-2 protein family and BH3 mimetics. (A) The effector proteins of the $\mathrm{Bcl}-2$ family, Bax and Bak, are inhibited by the anti-apoptotic proteins $\mathrm{Bcl}-2, \mathrm{Bcl}-\mathrm{w}, \mathrm{Bcl}-\mathrm{xl}$, and Mcl-1. Upon induction of apoptosis, the sensitizers BAD and NOXA inhibit the anti-apoptotic proteins. The activators BID, BIM, and PUMA can also block the anti-apoptotic proteins and can interact directly with Bax and Bak. Free effectors can then induce MOMP and apoptosis. (B) The BH3 mimetics are surrogate proteins to the activator and sensitizer BH3-only proteins. They can be divided into pan-BH3 mimetics [GX15-070, (-)-gossypol, BI-97Cl] antagonizing all members of the anti-apoptotic proteins, and specific BH3 mimetics (ABT-263/737), binding to Bcl-2, Bcl-xl, and Bcl-w, but not Mcl-1. Abbreviations: BAD, Bcl-2 antagonist of cell death; Bak, Bcl-2 antagonist/killer; Bax, Bcl-2 associated X protein; Bcl-2, B-cell lymphoma 2; Bcl-w, Bcl-2 like 2; Bcl-xl, B-cell lymphoma extra-large; BID, BH3 interacting domain death agonist; BIM, Bcl-2 interacting mediator of cell death; Mcl-1, myeloid cell leukemia sequence; MOMP, mitochondrial outer membrane permeabilization; NOXA, phorbol-12-myristate-13-acetate-induced protein 1; PUMA, p53 upregulated modulator of apoptosis. BH3 mimetics: ABT-263, Navitoclax; BI-97-Cl, Sabutoclax; GX15-070, Obatoclax.

inhibitor (HDACI), also heightened the cytotoxicity of (-)gossypol. Mechanistically, valproic acid enhanced the induction of mitochondrial stress, as shown by upregulation of glycolysisand hypoxia-associated proteins (Ouyang et al., 2011). (-)Gossypol also acted as a radiosensitizer in a study of $\mathrm{Xu}$ et al. (2005). The pan-BH3 mimetic enhanced the radiationinduced apoptosis of PC-3 cells, which were established from a PC bone metastasis, show androgen-independent growth and express high levels of Bcl-2 and Bcl-xl (Kaighn et al., 1979). Combination therapy led to tumor regression in a PC-3 mouse xenograft model, and anti-CD31 immunostaining evidenced that the combination therapy also inhibited tumor angiogenesis (Xu et al., 2005). Synergistic effects by the pan-BH3 mimetic Obatoclax with androgen receptor (AR) inactivation by the antiandrogen bicalutamide was observed in a study of Santer et al. (2015). The combination of BI-97CI (Sabutoclax) with an IL-10 family cytokine, called melanoma differentiation associated gene7/interleukin-24 (mda-7/Il-24), was marked by autophagy that facilitated NOXA and Bim-induced Bax/Bak mediated apoptosis.
This resulted in an enhanced cytotoxicity in PC cells and significant in vivo inhibition of tumor growth (Dash et al., 2011).

AT-101 was also tested in clinical trials against PC; however, the goals of the studies were not reached. AT-101 as single agent had only limited activity in 23 patients with chemotherapy naïve CRPC. Two patients of a phase I/II study had a confirmed $\geq$ post-therapeutic prostate-specific antigen decline. No objective responses were observed. Gastrointestinal toxicity was the main adverse side effect and was dose-limiting (Liu et al., 2009). In a phase II trial, AT-101 was combined with docetaxel/prednisone treatment in 221 patients with hormonenaïve, progressive CRPC. The median overall survival of patients treated with AT-101 was 18.1 months and not significantly different from patients treated with docetaxel/prednisone alone (17.8 months; HR 1.07; 95\% CI 0.72-1.55, $p=0.63$ ) (Sonpavde et al., 2012).

It is discussed that the low antitumor activity of the pan-BH3 mimetics and their dose-limiting adverse side effects in clinical 
trials might be based on their moderate affinity and low specificity for the anti-apoptotic Bcl-2 proteins (Vogler et al., 2009). For example, gossypol compounds were shown to induce apoptosis in BAX/BAK-deficient cells and elicited several off-target effects. It is therefore suggested that they might have more functions than only to act as pan-BH3 mimetics (Billard, 2013). The main focus is therefore actually on the use of specific $\mathrm{BH} 3$ mimetics.

\section{Specific BH3 Mimetics}

Specific BH3 mimetics, which were tested in PC cells to date, are ABT-737 and its orally administrable analog ABT263 (Navitoclax). They are BAD-like BH3 mimetics, which were rationally designed by structure-based drug design for binding the hydrophobic groove of $\mathrm{Bcl}$-xl (Oltersdorf et al., 2005). Like BAD, ABT-263/737 selectively bind with subnanomolar affinities to $\mathrm{Bcl}-2, \mathrm{Bcl}-\mathrm{xl}$, and $\mathrm{Bcl}-\mathrm{w}$, but not to Mcl-1 (Figure 1B) (Zhai et al., 2006). This means that ABT-263/737 are highly specific and cancer cells with high overexpression of endogenous $\mathrm{Bcl}-2$ or $\mathrm{Bcl}-\mathrm{xl}$ are particularly vulnerable.

An overview of preclinical studies with ABT-263/737 against $\mathrm{PC}$ is given in Table $\mathbf{1}$. Since the survival of prostate tumor cells is mainly dependent on $\mathrm{Bcl}-\mathrm{xl}$ and $\mathrm{Mcl}-1$, the rationale was given to combine the $\mathrm{BH} 3$ mimetics with agents that additionally degrade or neutralize Mcl-1 for the induction of apoptosis.

Some authors used the combination of ABT-263/ABT-737 with different chemotherapeutic agents to enhance efficacy and to overcome resistance. Wang and colleagues proved an enhanced Bcl-xl level as the reason for paclitaxel resistance in PC cells (Wang et al., 2015). Combination with ABT-263, which inhibited $\mathrm{Bcl}-\mathrm{xl}$, triggered the paclitaxel induced apoptosis. Different sensitivities to the $\mathrm{BH} 3$ mimetic were detected in
LNCaP and PC-3 cells, although both lines showed similar expression of the Bcl-2 family proteins. The authors therefore speculated that downstream elements, like unidentified proteins affecting MOMP, could be responsible for this observation (Wang et al., 2015). Docetaxel was found to increase cyclin B1/Cdk1-mediated phosphorylation of $\mathrm{Bcl}-2$ and $\mathrm{Bcl}-\mathrm{xl}$ and to decrease Mcl-1. This, however, was not enough alone to counteract the high levels of the anti-apoptotic proteins in PC-3 cells. Therefore, docetaxel was combined with ABT263/737, which led to an enhanced induction of apoptosis (Parrondo et al., 2013; Tamaki et al., 2014). Bray and colleagues developed a PC mouse model with tumorigenesis and apoptosis resistance based on overexpression of Bcl-2. They could show that taxane-mediated Bim induction was insufficient to exceed the apoptotic threshold conferred by Bcl-2 and used ABT-737 for chemosensitization of the tumors (Bray et al., 2009).

ABT-263 was also combined with the proteasome inhibitor MLN2238. Proteasome inhibitors are able to modulate pro-apoptotic factors, like p53 and NOXA, for the induction of apoptosis. Whereas ABT-263 and MLN2238 alone only showed a mild cytotoxicity in the highly metastatic and androgen-independent PC cell lines PC-3 and C4-2B, their combination led to synergistic effects. Molecular examinations showed that MLN2238 enhanced the NOXA levels, leading to an enhanced NOXA/Mcl-1 formation and dissociation of Bax from Mcl-1 (Wei et al., 2014).

A synthetic cell penetrating peptide, called CP-d/n-AFT5-S1, was used to inhibit the transcription factor 5 (ATF5) (KarpelMassler et al., 2016). ATF5 belongs to the cAMP responseelement binding protein (CREB) family and regulates the

TABLE 1 | Preclinical studies of BH3 mimetics in combination with different agents against PC cells eliciting additive or synergistic cytotoxicity.

\begin{tabular}{|c|c|c|c|}
\hline BH3 mimetic & Target & Combination with & Reference \\
\hline (-)-Gossypol & $\mathrm{Bcl}-2, \mathrm{Bcl}-\mathrm{xl}, \mathrm{Bcl}-\mathrm{w}, \mathrm{Mcl}-1$ & Docetaxel & Meng et al., 2008 \\
\hline (-)-Gossypol & $\mathrm{Bcl}-2, \mathrm{Bcl}-\mathrm{xl}, \mathrm{Bcl}-\mathrm{w}, \mathrm{Mcl}-1$ & Valproic acid & Ouyang et al., 2011 \\
\hline (-)-Gossypol & $\mathrm{Bcl}-2, \mathrm{Bcl}-\mathrm{xl}, \mathrm{Bcl}-\mathrm{w}, \mathrm{Mcl}-1$ & Radiation & Xu et al., 2005 \\
\hline GX15-070 & $\mathrm{Bcl}-2, \mathrm{Bcl}-\mathrm{xl}, \mathrm{Bcl}-\mathrm{w}, \mathrm{Mcl}-1$ & Bicalutamide & Santer et al., 2015 \\
\hline \multicolumn{4}{|c|}{ Specific BH3 mimetics } \\
\hline ABT-263 & $\mathrm{Bcl}-2, \mathrm{Bcl}-\mathrm{xl}, \mathrm{Bcl}-\mathrm{w}$ & Paclitaxel & Wang et al., 2015 \\
\hline ABT-737 & $\mathrm{Bcl}-2, \mathrm{Bcl}-\mathrm{xl}, \mathrm{Bcl}-\mathrm{w}$ & Docetaxel & Parrondo et al., 2013 \\
\hline ABT-263/737 & $\mathrm{Bcl}-2, \mathrm{Bcl}-\mathrm{xl}, \mathrm{Bcl}-\mathrm{w}$ & Docetaxel & Tamaki et al., 2014 \\
\hline ABT-737 & $\mathrm{Bcl}-2, \mathrm{Bcl}-\mathrm{xl}, \mathrm{Bcl}-\mathrm{w}$ & Cisplatin & Bray et al., 2009 \\
\hline ABT-263 & $\mathrm{Bcl}-2, \mathrm{Bcl}-\mathrm{xl}, \mathrm{Bcl}-\mathrm{w}$ & MLN2238 & Wei et al., 2014 \\
\hline ABT-737 & Bcl-2, Bcl-xl, Bcl-w & Pseudolaric acid B (PAB) & Tong et al., 2013 \\
\hline ABT-737 & $\mathrm{Bcl}-2, \mathrm{Bcl}-\mathrm{xl}, \mathrm{Bcl}-\mathrm{w}$ & Transcriptional inhibitor ARC & Pandit and Gartel, 2010 \\
\hline ABT-737 & $\mathrm{Bcl}-2, \mathrm{Bcl}-\mathrm{xl}, \mathrm{Bcl}-\mathrm{w}$ & MSeA & Yin et al., 2012 \\
\hline ABT-737 & $\mathrm{Bcl}-2, \mathrm{Bcl}-\mathrm{xl}, \mathrm{Bcl}-\mathrm{w}$ & TRAIL & Song et al., 2008 \\
\hline
\end{tabular}


transcription of Bcl-2 and Mcl-1 (Chen et al., 2012; Izumi et al., 2012). It is upregulated in many cancers and promotes apoptosis resistance (Monaco et al., 2007). CP-d/n-AFT5-S1 led to diminished levels of Bcl-2 and Mcl-1 in cancer cells of different origin, including PC, and acted synergistically with ABT-263. In a mouse model the combination therapy significantly reduced the growth of PC-3 tumor xenografts. Mechanistically, a decreased expression of the Mcl-1 interacting proteins Bag3 and Usp9X was observed after incubation with the inhibitor, which was followed by Mcl-1 depletion. Interestingly, CP-d/n-AFT5-S1 also increased the $\mathrm{Bcl}-\mathrm{xl}$ expression in some cell lines. The authors therefore discussed the possibility that the $\mathrm{Bcl}-\mathrm{xl}$ overexpression could render cancer cells more sensitive to ABT-263 (KarpelMassler et al., 2016).

In a further study, 2-deoxyglucose (2DG) was successfully combined with ABT-263/737 and inhibited the growth of mouse prostate tumor xenografts. It was found that $2 \mathrm{DG}$ primed the cells by interference with Mcl-1/Bak complexes, making it easier for the BH3 mimetics to free Bak from Bcl-2 (Yamaguchi et al., 2011).

Pim serine/threonine kinases promote the tumorigenesis of PC cells and contribute to the therapeutic resistance. Pim kinase inhibitors acted synergistically with ABT-737 in vitro and in vivo. The study proved that the Pim kinase inhibitors decreased the Mcl-1 levels by blocking $5^{\prime}$-cap dependent translation and reduction of the protein half-life. Moreover, they led to an enhanced transcription of NOXA, which blocked the remaining levels of Mcl-1 (Song and Kraft, 2012).

Pseudolaric acid B (PAB) is a plant-derived terpenoid, which shows antitumorous or chemopreventive activity in many types of cancer. PAB induced cell cycle arrest as well as a downregulation of $\mathrm{Bcl}-2$ and $\mathrm{Mcl}-1$ via the JNK-mediated cell death pathway, which is known to activate pro-apoptotic and to inactivate anti-apoptotic $\mathrm{Bcl}-2$ family proteins. As a result $\mathrm{PAB}$ acted synergistically with ABT-737 in PC cells (Tong et al., 2013).

The transcriptional inhibitor ARC (4-amino-6hydrazino-7- $\beta$-D-ribofuranosyl-7H-pyrrolo(2,3-d)-pyrimidine5-carboxamide) is an inhibitor of the P-TEFb kinase (CDK9/CyclinT1 complex). It was demonstrated that ARC effectively downregulated the Mcl-1 expression of PC cells and showed synergistic effects with ABT-737 (Pandit and Gartel, 2010).

The selenium compound methylseleninic acid (MSeA) has been reported to downregulate prostate-specific antigen expression via disruption of AR signaling (Dong et al., 2004; Zhao et al., 2004). MSeA led to a decreased Mcl-1 expression in DU145 cells and acted therefore synergistically with ABT-737. Remarkably, synergism was due to a dephosphorylation of BAD by MSeA, since phosphorylation of BAD at ser-136 and ser-112 was identified as an ABT-737 resistance mechanism (Yin et al., 2012).

Song and colleagues demonstrated that ABT-737 can directly influence the extrinsic apoptotic pathway (Song et al., 2008). Combination of the tumor necrosis factor-related apoptosisinducing ligand (TRAIL) with ABT-737 led to a synergistic cytotoxicity in PC cells. Interestingly, ABT-737 treatment was shown to enhance the expression of the TRAIL receptor DR5 via a transcriptional mechanism dependent on the NF-kappaB site of the DR5 promotor (Song et al., 2008).

Testing of ABT-737 in clinical trials against PC is ongoing. Recently, a phase II study of ABT-263 in combination with abiraterone or abiraterone/hydroxychloroquine in patients with CRPC following chemotherapy and abiraterone treatment has been terminated (Identifier: NCT01828476) ${ }^{1}$. Study results have not been published yet.

\section{CONCLUSIONS AND OUTLOOKS}

$\mathrm{BH} 3$ mimetics seem to be particularly suitable for the combination treatment of PC for several reasons. First, different preclinical studies have proven that $\mathrm{BH} 3$ mimetics are sensitizers for apoptosis in PC cells, which represent advanced stages of the disease and which are known to be resistant against apoptosis. Second, the intrinsic apoptotic pathway is involved in cell death caused by most of the chemotherapeutic drugs, toxins, antiandrogens, and irradiation, and $\mathrm{BH} 3$ mimetics are able to lower the threshold for its activation. Third, $\mathrm{BH} 3$ mimetics directly abrogate the interaction between pro- and anti-apoptotic Bcl-2 proteins, with a direct activation of the effectors Bax and Bak. This might be more promising than the use of antitumor drugs that act upstream. Fourth, Bax and Bak are expressed in nearly all PC cells in a non-mutated form and can therefore successfully be activated for the induction of apoptosis.

It is important to ensure the comprehensive blocking of all of the anti-apoptotic members of the Bcl-2 family for highest efficacy. This is in principle possible by using pan $\mathrm{Bcl}-2$ inhibitors. However, these molecules have a lower affinity to the target proteins than the specific Bcl-2 inhibitors, and high off-target side effects led to a lack of efficacy and to dose-limiting toxicities in clinical trials.

Specific BH3 mimetics like ABT-737 have the advantage to bind with higher affinity; however, might not be sufficient to induce apoptosis. Moreover, upregulation of non-targeted Bcl2 members could lead to resistance (Konopleva et al., 2006; Yecies et al., 2010). Specific Mcl-1 inhibitors (Small molecule Mcl-1 inhibitor, MIM-1, TW-37, A1210477, biphenyl-NOXA $\mathrm{BH} 3$ peptide) are therefore currently under investigation to be combined (Besbes et al., 2015).

Since $\mathrm{BH} 3$ mimetics developed so far are non-targeted molecules, off-target adverse side effects could endanger the success of clinical trials. The best way should therefore be to combine $\mathrm{BH} 3$ mimetics with tumor-specific agents to selectively attack the cancer cells. One such agent can be an immunotoxin consisting of an antibody fragment specifically binding to a tumor surface antigen and of the cytotoxic domain of Pseudomonas aeruginosa exotoxin A (PEA). PEA-based immunotoxins inhibit the protein biosynthesis of antigen-expressing cancer cells and especially downregulate Mcl-1 (Michalska and Wolf, 2015). Such immunotoxins, targeting mesothelin on pancreatic cancer cells or the transferrin receptor on small cell lung cancer cells, were

\footnotetext{
${ }^{1}$ ClinicalTrials.gov
} 
successfully combined with ABT-263/737 and induced death in cells that were shown to be resistant against the individual components (Mattoo and FitzGerald, 2013; Hollevoet et al., 2014). Table 1 demonstrates that only unspecific agents were added to the $\mathrm{BH} 3$ mimetics in the studies against PC. The combination of specific $\mathrm{BH} 3$ mimetics with targeted molecules, leading to an induction of apoptosis specifically in cancer cells, could therefore provide a successful route for an improved therapy of PC in future.

\section{REFERENCES}

Anvari, K., Seilanian Toussi, M., Kalantari, M., Naseri, S., Karimi Shahri, M., Ahmadnia, H., et al. (2012). Expression of Bcl-2 and Bax in advanced or metastatic prostate carcinoma. Urol. J. 9, 381-388.

Besbes, S., Mirshahi, M., Pocard, M., and Billard, C. (2015). New dimension in therapeutic targeting of BCL-2 family proteins. Oncotarget 6, 12862-12871. doi: 10.18632/oncotarget.3868

Billard, C. (2013). BH3 mimetics: status of the field and new developments. Mol. Cancer Ther. 12, 1691-1700. doi: 10.1158/1535-7163.MCT-13-0058

Boudny, V., and Nakano, S. (2002). Src tyrosine kinase augments taxotere-induced apoptosis through enhanced expression and phosphorylation of Bcl-2. Br. J. Cancer 86, 463-469. doi: 10.1038/sj.bjc.6600080

Bray, K., Chen, H. Y., Karp, C. M., May, M., Ganesan, S., Karantza-Wadsworth, V., et al. (2009). Bcl-2 modulation to activate apoptosis in prostate cancer. Mol. Cancer Res. 7, 1487-1496. doi: 10.1158/1541-7786.MCR-09-0166

Castilla, C., Congregado, B., Chinchon, D., Torrubia, F. J., Japon, M. A., and Saez, C. (2006). Bcl-xL is overexpressed in hormone-resistant prostate cancer and promotes survival of $\mathrm{LNCaP}$ cells via interaction with proapoptotic Bak. Endocrinology 147, 4960-4967. doi: 10.1210/en.2006-0502

Chen, A., Qian, D., Wang, B., Hu, M., Lu, J., Qi, Y., et al. (2012). ATF5 is overexpressed in epithelial ovarian carcinomas and interference with its function increases apoptosis through the downregulation of Bcl-2 in SKOV-3 cells. Int. J. Gynecol. Pathol. 31, 532-537. doi: 10.1097/PGP.0b013e31824df26b

Cory, S., Huang, D. C., and Adams, J. M. (2003). The Bcl-2 family: roles in cell survival and oncogenesis. Oncogene 22, 8590-8607. doi: 10.1038/sj.onc.1207102

Czabotar, P. E., Lessene, G., Strasser, A., and Adams, J. M. (2014). Control of apoptosis by the BCL-2 protein family: implications for physiology and therapy. Nat. Rev. Mol. Cell Biol. 15, 49-63. doi: 10.1038/nrm3722

Dash, R., Azab, B., Quinn, B. A., Shen, X., Wang, X. Y., Das, S. K., et al. (2011). Apogossypol derivative BI-97C1 (Sabutoclax) targeting Mcl-1 sensitizes prostate cancer cells to mda-7/IL-24-mediated toxicity. Proc. Natl. Acad. Sci. U.S.A. 108, 8785-8790. doi: 10.1073/pnas.1100769108

DiPaola, R. S., Patel, J., and Rafi, M. M. (2001). Targeting apoptosis in prostate cancer. Hematol. Oncol. Clin. North Am. 15, 509-524. doi: 10.1016/S08898588(05)70229-X

Dong, Y., Lee, S. O., Zhang, H., Marshall, J., Gao, A. C., and Ip, C. (2004). Prostate specific antigen expression is down-regulated by selenium through disruption of androgen receptor signaling. Cancer Res. 64, 19-22. doi: 10.1158/0008-5472. CAN-03-2789

Ferlay, J., Soerjomataram, I., Dikshit, R., Eser, S., Mathers, C., Rebelo, M., et al. (2015). Cancer incidence and mortality worldwide: sources, methods and major patterns in GLOBOCAN 2012. Int. J. Cancer 136, E359-E386. doi: 10.1002/ijc. 29210

Gjertsen, B. T., Logothetis, C. J., and Mcdonnell, T. J. (1998). Molecular regulation of cell death and therapeutic strategies for cell death induction in prostate carcinoma. Cancer Metastasis Rev. 17, 345-351. doi: 10.1023/A:1006170332301

Halabi, S., Lin, C. Y., Kelly, W. K., Fizazi, K. S., Moul, J. W., Kaplan, E. B., et al. (2014). Updated prognostic model for predicting overall survival in first-line chemotherapy for patients with metastatic castration-resistant prostate cancer. J. Clin. Oncol. 32, 671-677. doi: 10.1200/JCO.2013.52.3696

Hanahan, D., and Weinberg, R. A. (2011). Hallmarks of cancer: the next generation. Cell 144, 646-674. doi: 10.1016/j.cell.2011.02.013

Hollevoet, K., Antignani, A., FitzGerald, D. J., and Pastan, I. (2014). Combining the antimesothelin immunotoxin SS1P with the BH3-mimetic ABT-737 induces

\section{AUTHOR CONTRIBUTIONS}

PW prepared the whole manuscript.

\section{FUNDING}

This work was supported by the Wilhelm Sander Foundation (Grant No. 2016.089.1).

cell death in SS1P-resistant pancreatic cancer cells. J. Immunother. 37, 8-15. doi: 10.1097/CJI.0000000000000010

Izumi, S., Saito, A., Kanemoto, S., Kawasaki, N., Asada, R., Iwamoto, H., et al. (2012). The endoplasmic reticulum stress transducer BBF2H7 suppresses apoptosis by activating the ATF5-MCL1 pathway in growth plate cartilage. J. Biol. Chem. 287, 36190-36200. doi: 10.1074/jbc.M112.373746

Joudeh, J., and Claxton, D. (2012). Obatoclax mesylate: pharmacology and potential for therapy of hematological neoplasms. Expert Opin. Investig. Drugs 21, 363-373. doi: 10.1517/13543784.2012.652302

Kaighn, M. E., Narayan, K. S., Ohnuki, Y., Lechner, J. F., and Jones, L. W. (1979). Establishment and characterization of a human prostatic carcinoma cell line (PC-3). Invest. Urol. 17, 16-23.

Karpel-Massler, G., Horst, B. A., Shu, C., Chau, L., Tsujiuchi, T., Bruce, J. N., et al. (2016). A synthetic cell-penetrating dominant-negative ATF5 peptide exerts anticancer activity against a broad spectrum of treatment-resistant cancers. Clin. Cancer Res. 22, 4698-4711. doi: 10.1158/1078-0432.CCR15-2827

Katzenwadel, A., and Wolf, P. (2015). Androgen deprivation of prostate cancer: leading to a therapeutic dead end. Cancer Lett. 367, 12-17. doi: 10.1016/j.canlet. 2015.06.021

Kiraz, Y., Adan, A., Kartal Yandim, M., and Baran, Y. (2016). Major apoptotic mechanisms and genes involved in apoptosis. Tumour Biol. 37, 8471-8486. doi: 10.1007/s13277-016-5035-9

Konopleva, M., Contractor, R., Tsao, T., Samudio, I., Ruvolo, P. P., Kitada, S., et al. (2006). Mechanisms of apoptosis sensitivity and resistance to the BH3 mimetic ABT-737 in acute myeloid leukemia. Cancer Cell 10, 375-388. doi: 10.1016/j.ccr.2006.10.006

Krajewska, M., Krajewski, S., Epstein, J. I., Shabaik, A., Sauvageot, J., Song, K., et al. (1996). Immunohistochemical analysis of bcl-2, bax, bcl-X, and mcl-1 expression in prostate cancers. Am. J. Pathol. 148, 1567-1576.

Lebedeva, I., Rando, R., Ojwang, J., Cossum, P., and Stein, C. A. (2000). Bcl$\mathrm{xL}$ in prostate cancer cells: effects of overexpression and down-regulation on chemosensitivity. Cancer Res. 60, 6052-6060.

Lessene, G., Czabotar, P. E., and Colman, P. M. (2008). BCL-2 family antagonists for cancer therapy. Nat. Rev. Drug Discov. 7, 989-1000. doi: 10.1038/nrd2658

Lian, J., Ni, Z., Dai, X., Su, C., Smith, A. R., Xu, L., et al. (2012). Sorafenib sensitizes (-)-gossypol-induced growth suppression in androgen-independent prostate cancer cells via Mcl-1 inhibition and Bak activation. Mol. Cancer Ther. 11, 416-426. doi: 10.1158/1535-7163.MCT-11-0559

Liu, G., Kelly, W. K., Wilding, G., Leopold, L., Brill, K., and Somer, B. (2009). An open-label, multicenter, phase I/II study of single-agent AT-101 in men with castrate-resistant prostate cancer. Clin. Cancer Res. 15, 3172-3176. doi: 10.1158/1078-0432.CCR-08-2985

Mattoo, A. R., and FitzGerald, D. J. (2013). Combination treatments with ABT-263 and an immunotoxin produce synergistic killing of ABT-263-resistant small cell lung cancer cell lines. Int. J. Cancer 132, 978-987. doi: 10.1002/ijc.27732

Meng, Y., Tang, W., Dai, Y., Wu, X., Liu, M., Ji, Q., et al. (2008). Natural $\mathrm{BH} 3$ mimetic (-)-gossypol chemosensitizes human prostate cancer via $\mathrm{Bcl}-\mathrm{xL}$ inhibition accompanied by increase of Puma and Noxa. Mol. Cancer Ther. 7, 2192-2202. doi: 10.1158/1535-7163.MCT-08-0333

Michalska, M., and Wolf, P. (2015). Pseudomonas exotoxin A: optimized by evolution for effective killing. Front. Microbiol. 6:963. doi: 10.3389/fmicb.2015. 00963

Monaco, S. E., Angelastro, J. M., Szabolcs, M., and Greene, L. A. (2007). The transcription factor ATF5 is widely expressed in carcinomas, and interference 
with its function selectively kills neoplastic, but not nontransformed, breast cell lines. Int. J. Cancer 120, 1883-1890. doi: 10.1002/ijc.22469

Oltersdorf, T., Elmore, S. W., Shoemaker, A. R., Armstrong, R. C., Augeri, D. J., Belli, B. A., et al. (2005). An inhibitor of Bcl-2 family proteins induces regression of solid tumours. Nature 435, 677-681. doi: 10.1038/nature 03579

Ouyang, D. Y., Ji, Y. H., Saltis, M., Xu, L. H., Zhang, Y. T., Zha, Q. B., et al. (2011). Valproic acid synergistically enhances the cytotoxicity of gossypol in DU145 prostate cancer cells: an iTRTAQ-based quantitative proteomic analysis. J. Proteomics 74, 2180-2193. doi: 10.1016/j.jprot.2011.06.016

Pandit, B., and Gartel, A. L. (2010). New potential anti-cancer agents synergize with bortezomib and ABT-737 against prostate cancer. Prostate 70, 825-833. doi: $10.1002 /$ pros.21116

Parrondo, R., De Las Pozas, A., Reiner, T., and Perez-Stable, C. (2013). ABT737, a small molecule $\mathrm{Bcl}-2 / \mathrm{Bcl}-\mathrm{xL}$ antagonist, increases antimitotic-mediated apoptosis in human prostate cancer cells. PeerJ 1:e144. doi: 10.7717/peerj.144

Petrylak, D. P., Tangen, C. M., Hussain, M. H., Lara, P. N. Jr., Jones, J. A., Taplin, M. E., et al. (2004). Docetaxel and estramustine compared with mitoxantrone and prednisone for advanced refractory prostate cancer. N. Engl. J. Med. 351, 1513-1520. doi: 10.1056/NEJMoa041318

Pienta, K. J. (2001). Preclinical mechanisms of action of docetaxel and docetaxel combinations in prostate cancer. Semin. Oncol. 28, 3-7. doi: 10.1016/S00937754(01)90148-4

Reiner, T., De Las Pozas, A., Parrondo, R., Palenzuela, D., Cayuso, W., Rai, P., et al. (2015). Mcl-1 protects prostate cancer cells from cell death mediated by chemotherapy-induced DNA damage. Oncoscience 2, 703-715. doi: 10.18632/ oncoscience.231

Santer, F. R., Erb, H. H., Oh, S. J., Handle, F., Feiersinger, G. E., Luef, B., et al. (2015). Mechanistic rationale for MCL1 inhibition during androgen deprivation therapy. Oncotarget 6, 6105-6122. doi: 10.18632/oncotarget.3368

Scarfo, L., and Ghia, P. (2013). Reprogramming cell death: BCL2 family inhibition in hematological malignancies. Immunol. Lett. 155, 36-39. doi: 10.1016/j.imlet. 2013.09.015

Song, J. H., Kandasamy, K., and Kraft, A. S. (2008). ABT-737 induces expression of the death receptor 5 and sensitizes human cancer cells to TRAIL-induced apoptosis. J. Biol. Chem. 283, 25003-25013. doi: 10.1074/jbc.M802511200

Song, J. H., and Kraft, A. S. (2012). Pim kinase inhibitors sensitize prostate cancer cells to apoptosis triggered by Bcl-2 family inhibitor ABT-737. Cancer Res. 72, 294-303. doi: 10.1158/0008-5472.CAN-11-3240

Sonpavde, G., Matveev, V., Burke, J. M., Caton, J. R., Fleming, M. T., Hutson, T. E., et al. (2012). Randomized phase II trial of docetaxel plus prednisone in combination with placebo or AT-101, an oral small molecule Bcl-2 family antagonist, as first-line therapy for metastatic castrationresistant prostate cancer. Ann. Oncol. 23, 1803-1808. doi: 10.1093/annonc/ mdr555

Stein, C. A. (1999). Mechanisms of action of taxanes in prostate cancer. Semin. Oncol. 26, 3-7.

Sweeney, C. J., Chen, Y. H., Carducci, M., Liu, G., Jarrard, D. F., Eisenberger, M., et al. (2015). Chemohormonal therapy in metastatic hormone-sensitive prostate cancer. N. Engl. J. Med. 373, 737-746. doi: 10.1056/NEJMoa1503747

Tamaki, H., Harashima, N., Hiraki, M., Arichi, N., Nishimura, N., Shiina, H., et al. (2014). Bcl-2 family inhibition sensitizes human prostate cancer cells to docetaxel and promotes unexpected apoptosis under caspase-9 inhibition. Oncotarget 5, 11399-11412. doi: 10.18632/oncotarget.2550

Tannock, I. F., De Wit, R., Berry, W. R., Horti, J., Pluzanska, A., Chi, K. N., et al. (2004). Docetaxel plus prednisone or mitoxantrone plus prednisone for advanced prostate cancer. N. Engl. J. Med. 351, 1502-1512. doi: 10.1056/ NEJMoa040720

Tong, J., Yin, S., Dong, Y., Guo, X., Fan, L., Ye, M., et al. (2013). Pseudolaric acid $\mathrm{B}$ induces caspase-dependent apoptosis and autophagic cell death in prostate cancer cells. Phytother. Res. 27, 885-891. doi: 10.1002/ptr.4808
Vogler, M., Weber, K., Dinsdale, D., Schmitz, I., Schulze-Osthoff, K., Dyer, M. J., et al. (2009). Different forms of cell death induced by putative BCL2 inhibitors. Cell Death Differ. 16, 1030-1039. doi: 10.1038/cdd.2009.48

Volate, S. R., Kawasaki, B. T., Hurt, E. M., Milner, J. A., Kim, Y. S., White, J., et al. (2010). Gossypol induces apoptosis by activating p53 in prostate cancer cells and prostate tumor-initiating cells. Mol. Cancer Ther. 9, 461-470. doi: 10.1158/1535-7163.MCT-09-0507

Wang, C., Huang, S. B., Yang, M. C., Lin, Y. T., Chu, I. H., Shen, Y. N., et al. (2015). Combining paclitaxel with ABT-263 has a synergistic effect on paclitaxel resistant prostate cancer cells. PLoS ONE 10:e0120913. doi: 10.1371/journal. pone. 0120913

Wei, J., Stebbins, J. L., Kitada, S., Dash, R., Placzek, W., Rega, M. F., et al. (2010). BI-97C1, an optically pure Apogossypol derivative as pan-active inhibitor of antiapoptotic B-cell lymphoma/leukemia-2 (Bcl-2) family proteins. J. Med. Chem. 53, 4166-4176. doi: 10.1021/jm1001265

Wei, X., Zhou, P., Lin, X., Lin, Y., Wu, S., Diao, P., et al. (2014). MLN2238 synergizes BH3 mimetic ABT-263 in castration-resistant prostate cancer cells by induction of NOXA. Tumour Biol. 35, 10213-10221. doi: 10.1007/s13277014-2333-y

Wolf, P. (2017). Treatment of metastatic prostate cancer after STAMPEDE. Transl. Androl. Urol. 6, 315-316. doi: 10.21037/tau.2017.02.01

Wolter, K. G., Wang, S. J., Henson, B. S., Wang, S., Griffith, K. A., Kumar, B., et al. (2006). (-)-Gossypol inhibits growth and promotes apoptosis of human head and neck squamous cell carcinoma in vivo. Neoplasia 8, 163-172. doi: 10.1593/neo.05691

Xu, L., Yang, D., Wang, S., Tang, W., Liu, M., Davis, M., et al. (2005). (-)-Gossypol enhances response to radiation therapy and results in tumor regression of human prostate cancer. Mol. Cancer Ther. 4, 197-205.

Yamaguchi, R., Janssen, E., Perkins, G., Ellisman, M., Kitada, S., and Reed, J. C. (2011). Efficient elimination of cancer cells by deoxyglucose-ABT-263/737 combination therapy. PLoS ONE 6:e24102. doi: 10.1371/journal.pone.0024102

Yecies, D., Carlson, N. E., Deng, J., and Letai, A. (2010). Acquired resistance to ABT-737 in lymphoma cells that up-regulate MCL-1 and BFL-1. Blood 115, 3304-3313. doi: 10.1182/blood-2009-07-233304

Yin, S., Dong, Y., Li, J., Fan, L., Wang, L., Lu, J., et al. (2012). Methylseleninic acid potentiates multiple types of cancer cells to ABT-737-induced apoptosis by targeting Mcl-1 and Bad. Apoptosis 17, 388-399. doi: 10.1007/s10495-0110687-9

Yoshino, T., Shiina, H., Urakami, S., Kikuno, N., Yoneda, T., Shigeno, K., et al. (2006). Bcl-2 expression as a predictive marker of hormone-refractory prostate cancer treated with taxane-based chemotherapy. Clin. Cancer Res. 12 , 6116-6124. doi: 10.1158/1078-0432.CCR-06-0147

Youle, R. J., and Strasser, A. (2008). The BCL-2 protein family: opposing activities that mediate cell death. Nat. Rev. Mol. Cell Biol. 9, 47-59. doi: 10.1038/nrm2308

Zhai, D., Jin, C., Satterthwait, A. C., and Reed, J. C. (2006). Comparison of chemical inhibitors of antiapoptotic Bcl-2-family proteins. Cell Death Differ. 13, 1419-1421. doi: 10.1038/sj.cdd.4401937

Zhao, H., Whitfield, M. L., Xu, T., Botstein, D., and Brooks, J. D. (2004). Diverse effects of methylseleninic acid on the transcriptional program of human prostate cancer cells. Mol. Biol. Cell 15, 506-519. doi: 10.1091/mbc.E03-07-0501

Conflict of Interest Statement: The author declares that the research was conducted in the absence of any commercial or financial relationships that could be construed as a potential conflict of interest.

Copyright (c) 2017 Wolf. This is an open-access article distributed under the terms of the Creative Commons Attribution License (CC BY). The use, distribution or reproduction in other forums is permitted, provided the original author(s) or licensor are credited and that the original publication in this journal is cited, in accordance with accepted academic practice. No use, distribution or reproduction is permitted which does not comply with these terms. 